\title{
Teacher vision: expert and novice teachers' perception of problematic classroom management scenes
}

\author{
Charlotte E. Wolff ${ }^{1} \cdot$ Halszka Jarodzka ${ }^{1,2} \cdot$ Niek van den Bogert ${ }^{3} \cdot$ \\ Henny P. A. Boshuizen ${ }^{1,4}$
}

Received: 10 February 2015/Accepted: 17 December 2015/Published online: 8 February 2016

(C) The Author(s) 2016. This article is published with open access at Springerlink.com

\begin{abstract}
Visual expertise has been explored in numerous professions, but research on teachers' vision remains limited. Teachers' visual expertise is an important professional skill, particularly the ability to simultaneously perceive and interpret classroom situations for effective classroom management. This skill is complex and relies on an awareness of classroom events. Using eye tracking measurements and verbal think aloud, we investigated differences in how expert and novice teachers perceive problematic classroom scenes. Sixty-seven teachers participated, 35 experienced secondary school teachers (experts) and 32 teachers-in-training (novices). Participants viewed videos of authentic lessons and their eye movements were recorded as they verbalized thoughts about what they had seen in the lesson and how it was relevant to classroom management. Two different types of videos were viewed: lesson fragments showing (1) multiple events depicting disengaged students with no overt disruptions and (2) multiple events that included a prominent disruptive event affecting the class. Analysis of eye movements showed that novices' viewing was more dispersed whereas experts' was more focused. Irrespective of the video type, expert teachers focused their attention on areas where relevant information was available, while novice teachers' attention was more scattered across the classroom. Experts' perception appears to be more knowledge-driven whereas novices' appears more image-driven. Experts monitored more areas than novices, while novices skipped more areas than experts. Word usage also differed, showing that expertise was associated with a higher frequency of words referencing cognition, perception, and events than novices.
\end{abstract}

Charlotte E. Wolff

charlottewolff@yahoo.com

1 Welten Institute, Research Centre for Learning, Teaching, and Technology, Open University of the Netherlands, P.O. Box 2960, 6401 Heerlen, DL, The Netherlands

2 The Eye-Tracking Group, The Humanities Laboratory, Lund University, Lund, Sweden

3 Eindhoven School of Education, Eindhoven University of Technology, Eindhoven, Netherlands

4 Faculty of Education University of Turku, University of Turku, Turku, Finland 
Keywords Teacher expertise $\cdot$ Classroom management $\cdot$ Professional vision $\cdot$ Eye tracking $\cdot$ Classroom perception

\section{Introduction}

Classrooms are full of complicated situations. At any given moment, there is a staggering amount of visually complex information teachers need to process to understand what is happening. Making sense of the classroom involves observing students behaviour, monitoring interactions between students, keeping up the pace of instruction, making snap decisions about how to intervene in classroom disruptions, and other pedagogical concerns. Managing the diversity of classroom interactions and attending to the cues and events which are most relevant for understanding them hinges on sophisticated cognitive processing (Berliner 2001; Copeland et al. 1994; Van Es and Sherin 2002).

An immense quantity of varied, fast-paced, co-occurring classroom events characterize the complexity of perceiving and processing a classroom: namely, the visual demands of simultaneity, multidimensionality, and immediacy in classrooms (Sabers et al. 1991). Kounin (1970) described the ability to remain aware of what is going on in the classroom as withitness. He suggested that teachers direct attention to relevant information in the classroom and continually monitor the progression of events to manage all that goes on in the classroom. Part of this understanding is reliant on the detection of visual cues and events, which can be defined as the signals, or hints, and actions that a teacher perceives, either consciously or unconsciously, and uses to make sense of what they see happening in a classroom. Withitness is underpinned by the cues and events that a teacher notices. Being 'withit' also relies on cognitive competencies that develop through practice, alongside the knowledge gained while teaching in classrooms (Berliner 2001). It requires continually monitoring classroom scenes to interpret and understand cues and events, guided by a cohesive integration of classroom knowledge and pedagogical knowledge. This integrated cognitive processing is informed by teachers' visual and perceptual abilities.

\section{Teacher expertise: knowledge and vision}

Although consensus on generic distinctions between expert and novice teachers is lacking, it is widely accepted that teacher expertise influences cognition and representation, depth of content knowledge, and goal-focused thinking (Hogan et al. 2003). Expert teachers have shown efficient information-reduction abilities when interpreting classroom complexity, even in classroom scenes that were previously unknown to them. This has been attributed to a difference in the event-structured knowledge of experts (Carter et al. 1988).

Teachers use pedagogical knowledge gained through experience to organize information into meaningful units. Expert teachers attend to different facts and interpret information differently than novices (Rink et al. 1994). Multiple studies have revealed that experts often integrate concerns of teaching and learning when analysing classroom events, while novices tend to consider surface-level concerns, such as teacher and student characteristics or behaviour and disciplinary issues (Tsui 2003). In their study investigating the strategies teachers use when viewing classroom videos, Colestock and Sherin (2009) determined that the majority of events noticed and commented upon by teachers concerned 
issues of pedagogy, classroom climate, and classroom management. This suggests that maintaining an effective classroom climate and managing the classroom is closely connected to the events perceived by teachers, and the visual processing therein.

One strategy that teachers use to deal with the demands of the classroom is to simplify the complexity by being selective about the events towards which they devote their attention and differentiating the significance of classroom events (Doyle 1977). Such selectivity relies heavily on a teachers' observations skills and visual perception. While teachers visual processing has not been as extensively researched as other professional domains, it is clear that knowledge and expertise are influential factors in visual processing across professions, such as medicine and chess (Reingold and Sheridan 2011). Experts are adept at seeing meaningful patterns within their domain (Boshuizen 2009; Lesgold et al. 1988). They make faster decisions and show greater accuracy on domain related tasks. Similarly, a teachers' expertise level influences perception and integration of visual information. "Expert teachers can readily recognize patterns in classroom events and hence make sense of them because of their hundreds and thousands of hours of experience in the classroom" (Tsui 2003, p. 33).

Professional vision and perceptions are shaped by an individual's particular experiences-one's mental representations of events, which are reconstructed and updated through experience, are preconditions for understanding (Goodwin 1994; Zacks and Tversky 2001). Experts possess knowledge enabling them to efficiently distinguish relevant from irrelevant information and focus on what is important in the situation at hand (Haider and Frensch 1996; van Meeuwen et al. 2014). Expert teachers have sophisticated, contextualized knowledge of classrooms events, are better able to adaptively integrate their pedagogical knowledge of types of events and students, and are more perceptive to the multidimensional complexity of classroom situations (Berliner 2001; Carter et al. 1988; Hattie 2003). Novices must consider the potential impact of all available information, and actively search for it, because they have not yet developed the knowledge allowing for efficient and effective cognitive processing (cf. Boshuizen and Schmidt 2008; Haider and Frensch 1996). Thus, the abundant practical classroom experience and ensuing knowledge of experts is likely to influence their ability to search for relevant cues in a focused, efficient manner, whereas novice teachers are likely to engage in a time-consuming, rather indiscriminate search for information.

\section{Managing and monitoring the classroom}

Classroom management has been succinctly defined as "the actions teachers take to create an environment that supports and facilitates both academic and social-emotional learning" (Evertson and Weinstein 2006, p. 4). Skilled classroom management combines classroom knowledge with pedagogical knowledge for handling classroom events and interactions to ensure that learning takes place. Teachers are under pressure not only to plan educational activities, but also to monitor their effectiveness within the classroom-an environment typified by multidimensionality (many events and actors), simultaneity (many things happening at the same time), and immediacy (the fast pace of these events) (Doyle 2006). Seeing and understanding the meaning of events amidst these conditions is crucial to classroom management, and it depends upon teachers' keen observational and perceptual abilities (Carter et al. 1988). To manage the classroom, teachers must observe the relevant cues and events, make sense of them quickly, monitor the progression of events, and 
ultimately make effective pedagogical decisions based upon this informational intake. These skills are consequential, as efficient classroom management has been shown to predict higher student achievement gains, higher levels of learning support, and gains in students' enjoyment (Kunter et al. 2013).

The 'professional vision' of teachers - their skilfulness at observing, searching for, and making sense of classroom scenes-develops over time as they learn the visual practices particular to their profession (Goodwin 1994; Sherin 2001). It is what allows experienced teachers to seek and monitor meaningful information. Eye tracking offers a useful methodology for investigating teachers' perceptual attention and professional vision; measures such as fixations can be used to identify where a teacher directs their attention and processes visual information. van den Bogert et al. (2014) used eye tracking fixations to contrast experienced and pre-service teachers' perception and detection of classroom events. Not only did expertise groups differ in the number of detected (potential) events, they also differed in their interpretation and viewing strategies. In those scenes where both groups identified considerable numbers of (potential) classroom management events, experienced teachers had shorter fixations and more frequent student check-ups than preservice teachers (i.e., they monitored more of the classroom). The researchers confirmed that experienced teachers have faster processing times than pre-service teachers, and theorized that when inexperienced teachers fail to notice an event, they continue scanning the classroom. Yet the research did not identify which areas are monitored, which kinds of interactional cues are relevant, and which areas are skipped. Nor did they address how this viewing activity differs between expertise groups.

\section{Processing classroom scenes}

Classrooms can be characterized as complex scenes. What a teacher notices and where a teacher fixates attention in the classroom is guided not only by the events occurring in the classroom, but also by the collection of experiences in classrooms, and the knowledge developing through these experiences. "The sense that a teacher makes of a particular scene is a product of ordered prior knowledge of classroom scenes, awareness of particular features of a present scene, and cognitive processes that connect knowledge with current awareness" (Carter et al. 1987 p. 149).

While capturing the gist of a scene requires only a single glance, searching for details that guide scene interpretation requires moving and steadying one's eyes. A viewer's preexisting knowledge guides and organizes what is seen within a particular scene, shaping the kinds of goals, elements and events perceived, and helps construct a plausible interpretation from the available information (Zacks and Tversky 2001). The attention of the viewer is central to how a scene is visually processed, and eye movements offer insight into attention allocation in scenes. Where a person looks directly relates to what they are processing cognitively (Just and Carpenter 1976).

Salient features of the image itself-bottom-up, image-driven processing-such as luminosity, colour, orientation and non-uniformity, can influence eye movements (Itti and Koch 2000). At the same time, cognition-top-down, knowledge-driven processing-also exerts a powerful influence (Yarbus 1967). Eyes are automatically drawn to informative areas of a scene, and what is considered informative depends on a viewer's knowledge. Knowledge arising through experience shapes how one perceives and conceives of events, such that "Effects of familiarity and expertise development show that experience exerts 
pervasive influence on event conception (Zacks and Tversky 2001, p. 18)". A person's event-structured knowledge about a particular kind of scene, such as a classroom, governs where the eyes move, even controlling the very first movement as one begins to perceive a scene (Henderson 2011; Rayner 2009).

Thus, differences in knowledge and expertise lead to divergences in the way expert and novice teachers' process classroom scenes. Experts can maintain a broad awareness of classroom scenes and events, while novices can be easily overwhelmed by the complexity of incoming information (Sabers et al. 1991; Tsui 2003). In terms of attention distribution, pre-service (novice) teachers have been shown to devote more than half of their viewingtime to only one student, whereas experienced (expert) teachers distribute attention more evenly across groups of students, engaging in continual monitoring of the classroom (van den Bogert et al. 2014). Novices can also be unaware of the behavioural and attentional cues that experts pick up on in order to prevent disruptions, or to adaptively resolve disruptions when they occur (Westerman 1991). In a recent study investigating teachers' awareness of student behaviour using eye tracking measures, teachers with varying years of experience were compared to determine whether or not they noticed two students who did not follow the teacher's instruction to close their textbook (Yamamoto and ImaiMatsumura 2013). No relationship between awareness of target students and years of teaching experience was found. It was shown, however, that teachers who were aware of the targeted misbehaviour had significantly more fixations on the target students than those who were unaware, and that their fixations were longer. Contrary to existing expertise and teaching research, the authors suggested that the noticing, or encoding, of student cues is unrelated to teaching experience, and attributed the interpretation of cues to teachers' information processing while teaching. The research presented in this study challenges this conclusion by asserting (1) that teaching experience does, indeed, influence noticing, processing, and interpreting classroom scenes and (2) that awareness of whether or not students' closed their textbook conveys a limited conceptualization of classroom management (Brophy 1999; Woolfolk-Hoy and Weinstein 2006).

While research consistently shows that expert teachers have valuable classroom knowledge about students and events that allows them to effectively detect and interpret events to manage classroom complexity, we know little about where teachers perceive relevant events and how they make use of their classroom perceptions (Carter et al. 1988). Existing classroom research has not isolated basic features of teachers visual processing, such as where teachers' find relevant cues and information, how teachers monitor students, where they look most frequently when processing classroom problems, and where they tend to skip or ignore information. Understanding the particularities of expert-novice differences when recognizing classroom cues is likewise limited (Behets 1996; van den Bogert et al. 2014).

\section{Research questions}

Teaching experience directly influences how classroom information is processed, including how teachers integrate and respond to the student interactions they observe (Behets 1996; Carter et al. 1988; Hattie 2003, 2012; Livingston and Borko 1989; Sabers et al. 1991). We assume that experience in classroom teaching can account for differences in the visual processing of teachers. As Van Es and Sherin (2002) have explained, key elements of noticing relate to the ability to identify what is important in classroom scenes, how knowledge for reasoning about interactions is applied to context, and how classroom interactions are connected to concepts of teaching and learning. Thus, the information a 
teacher notices, and how this information is interpreted, is directly linked to what is perceived as problematic and how problems can be managed to facilitate learning. Classroom management includes strategies for reducing conflicts and disruptions to teaching and learning, i.e., problematic events. Experts' knowledge of classroom situations allows for focused noticing, directing attention to relevant, informative areas, including student interactions, to interpret classroom events (Berliner 2001). Novices' limited classroom experience and event knowledge restricts their ability to selectively focus attention, making them likely to look all over the classroom to detect any cues that might be useful for building a plausible interpretation of events (Haider and Frensch 1996). In brief, we assert that the classroom perception of expert teachers' is more likely to be knowledge-driven, whereas novices' search is likely to be more image-driven.

Our study investigates how differences in teaching experience affect the way expert and novice teachers view classroom scenes and visually process the classroom management information noticed within these scenes. Eye tracking measures offer a useful means of exposing the visual processing and perceptual cues that teachers use to interpret classroom scenes and were used to identify expertise-based differences in the visual processing of the classroom. Verbal data were used to identify basic differences in teachers' word usage when thinking aloud about classroom management and to inform interpretation of eye tracking data.

The motivation driving our exploratory analysis was to understand the extent to which experience in the classroom influences teachers' visual perception and subsequent viewing strategies. The overarching question we investigated was: How does experience influence teachers' visual processing of the classroom?

1. Do experts and novices differ in their distribution of fixations when viewing classroom scenes?

2. Do experts and novices differ in terms of (a) areas they monitor, and (b) areas where they do not look?

3. Do expert' and novices differ in terms of word usage expressing mental/perceptual and action/event processing?

The first two research questions will be addressed by means of tracking participants' eye movements, and the third will be addressed by participants' verbalizations of their thoughts (for details see below).

\section{Methods}

\section{Participants}

Sixty-seven teachers (26 females; 41 males) from diverse subject domains (Language, History, Geography, Math, Biology, Economy, and Information Technology) participated in this study: 35 experienced teachers from six secondary schools in the Netherlands (i.e., experts: $M_{\text {age }}=49.2, S D=10.3$ ), and 32 pre-service teachers from a Dutch teacher training program (i.e., novices: $M_{\text {age }}=20.6, S D=2.3$ ). Due to data quality concerns and issues of missing data, eye movement data from five experts and two expert think aloud verbalizations were excluded from analysis.

While years of experience alone does not necessarily equate to being an expert teacher, research shows that competency generally develops within the first few years of teaching, and that five to seven years of experience is a reasonable estimate of the time it takes to develop a high level skill and knowledge as a teacher (Berliner 2004). Experts in this study 
had at least seven years of teaching experience, were recognized by fellow teachers as competent or above-average classroom managers, and were recommended by their school leaders as experts in the teaching profession (Palmer et al. 2005). Novices were in either the first or second year of teacher training and had completed between 10 and 40 hours of classroom teaching experience in the context of their training program. Participation was voluntary; experts were recruited in coordination with school directors motivated to engage in teaching research and novices were recruited through a local teacher training program.

\section{Materials and apparatus}

Stimuli were presented using Experiment Center 3.0. Eye movements were recorded with a remote SMI eye tracking system with a temporal resolution of $250 \mathrm{~Hz}$ (SMI RED250) using iView X 3.0 software. Videos were shown on a 22 -inch screen with a resolution $1680 \times 1050$ pixels; video stimulated verbalizations were recorded using a standard microphone attached to the laptop. An initial 13-point calibration of the eye tracker was performed at the start of the experiment, and 5-point validations were conducted prior to presenting subsequent video stimuli.

\section{Videos}

Video scenes are useful for conveying the multidimensionality, simultaneity, and richness of events within classrooms (Colestock and Sherin 2009). Two different types of video fragments (2-4 minutes each), which were clips from actual lessons, were used as stimuli. Each fragment was intended to display multiple events connected to classroom management concerns, and showed situations that would not require a teaching background in the subject being taught. All video was filmed from the perspective of the teacher in a static position (no panning or zooming was involved) and showed Dutch secondary school pupils in typical classrooms. They were selected by independent teacher trainers based on criteria defining two types of classroom scenarios in two different classes.

In total, four videos were shown. Two Type 1 videos, shown first, displayed multiple but seemingly unrelated classroom events and interactions. These were followed by two Type 2 videos displaying a prominent and pronounced classroom problem alongside multiple, interrelated events and interactions. The first type showed classroom scenarios where students appeared distracted and disengaged from the lesson at hand, but without an overt behavioural disruption in the lesson. The second type also showed students detached from the lesson, but, in contrast to the preceding videos, included prominent problematic classroom disruptions. For example, students who were blatantly ignoring the instruction of the teacher and leading other students astray in the lesson by throwing wadded paper or sustaining contact and waving to friends in the hallway. While both video types portrayed scenes where classroom management had gone off course and many students were not actively learning, the main difference between the two was the degree to which student disruptions were visible and the level of interconnectedness between events that made teaching and learning problematic (Fig. 1).

\section{Procedure}

The full experiment took approximately $50 \mathrm{~min}$. Prior to beginning the experiment, demographic data pertaining to age, teaching experience, subject-matters taught or being 


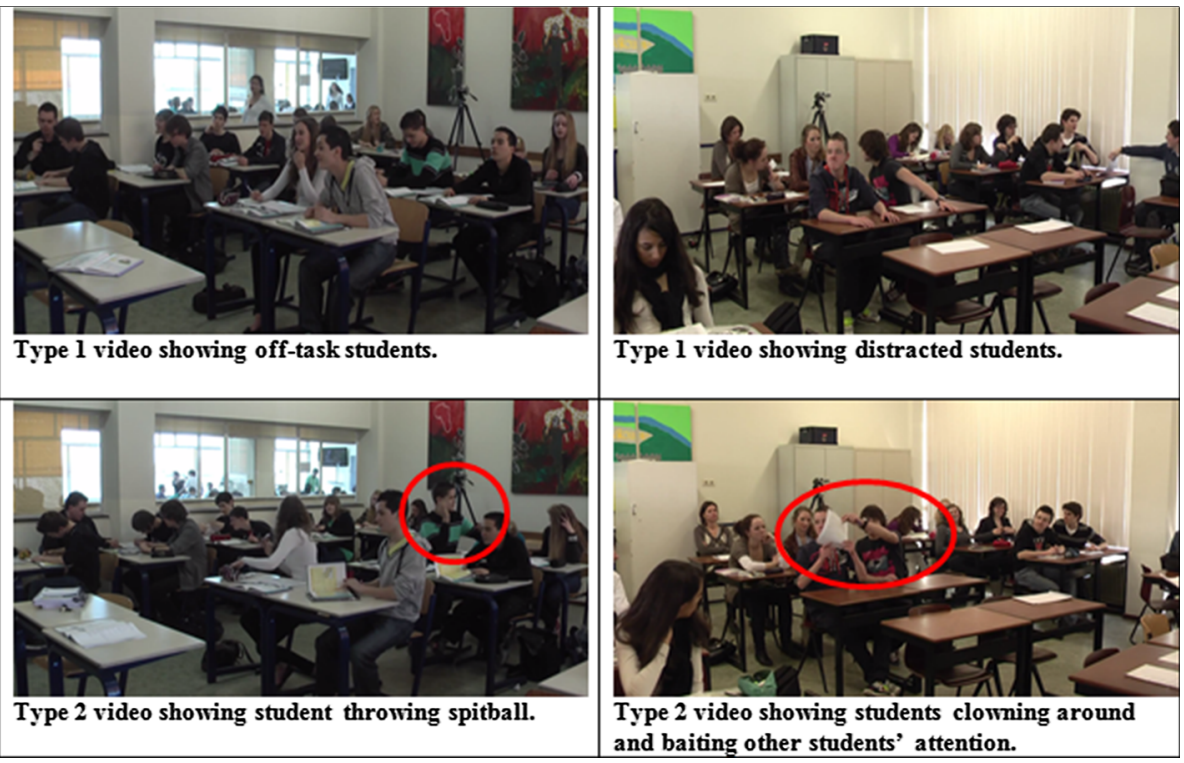

Fig. 1 Still shots from the two different lessons and video types used in the experiment. Type 1 videos showed disengaged students but lacked overtly disruptive events while Type 2 videos showed disengaged students and featured a conspicuous problematic event.

studied, and contact information were collected and consent and release forms were signed. The Miles Test, which determines one's dominant eye, was performed and participants were familiarized with the eye tracking equipment (Holmqvist et al. 2011) as well as the think aloud method (Ericsson and Simon 1980). Participants were informed that they would be viewing different classroom situations. They were asked to imagine themselves as teachers in these lessons and to think aloud about any issues in the classroom that they found relevant to classroom management.

Participants viewed each video twice. The first viewing familiarized them with the video content - they were unfamiliar with the classroom, lesson content, teacher, and students appearing in the video-making it easier to verbalize during the second viewing. The second viewing occurred immediately after the first viewing. They received the prompt "We will play the video a second time. While the video is playing, please think aloud and express what you were thinking when you saw the video for the first time." When there were prolonged silences during the verbalizations, participants were prompted to continue speaking with questions such as "Do you have anything more you'd like to say?" or "Is there anything you'd like to add?" They were free to talk as long as they wanted, even after the video fragment had ended. To replicate the time constraints of real-world classroom monitoring, each video was played at normal speed and participants were not allowed to stop or slow down the video during the experiment. Participants' eye movements were recorded each time they viewed the videos. This study reports only on eye movements made as they engaged in video-stimulated think aloud about the classroom scenes, when visual processing was linked directly to the verbal interpretations. 


\section{Data analysis}

Eye tracking data were analysed with BeGaze software (version 3.0), which detects eye movement events such as fixations. The velocity algorithm for fixation detection had a minimum setting of $50 \mathrm{~ms}$. A fixation is a relatively still, steady gaze when the eye takes-in and processes information (Holmqvist et al. 2011). Fixations tend to concentrate on subjectively informative areas (Yarbus 1967) and they allow viewers to identify objects, perceive visual features, and cognitively process scenes in a coherent way (Henderson 2011). They are particularly useful for identifying where teachers focus attention, where they repeatedly monitor information, what they find informative, and what they ignore.

\section{Research question 1}

To investigate the extent to which teachers' fixations were distributed (or not) as they perceived the classroom, participants' fixation dispersion average was calculated. This measure determines the extent to which participants' eye movements are spread out or focused while viewing a scene, providing a measure for gaze distribution (Holmqvist et al. 2011).

\section{AOI grid analysis}

For the next research questions eye movement data had to be linked to the video stimuli. Given the scarcity of studies applying eye tracking methodology to teaching expertise, we had no a priori hypotheses about where teachers would fixate and what teacher expertise groups would find informative. We therefore conducted an exploratory analysis to identify such features. Analysis software imposed $8 \times 8$ grids onto each video, spatially segmenting the stimuli screen into 64 equally-sized Areas of Interest (AOIs). AOIs are regions of the video in which various eye movement data are summarized and were used to identify locations on the screen where fixations were registered. The size of the AOI grids were large enough to spatially distinguish features of the classroom, such as rows of desks, areas with or without classroom activity, and different groups of students. This made it possible to interpret the visual information present in a particular area. Pre-defined semantic AOIs were avoided for several reasons. The video fragments were identified by experienced teacher trainers as containing multiple relevant events, and, as naturalistic stimuli, the fragments depicted multiple events occurring simultaneously, often in progression, rather than as isolated targeted events occurring at a precise moment in time. The spatial and temporal boundaries of events are notoriously fuzzy, and often vary from one person's point of view to another (Zacks et al. 2007). In short, there were no singularly objective events in the video fragments with clear onsets in space and time to substantiate predefined AOIs.

\section{Research question 2}

Number of revisits, calculated as the number of return fixations to an AOI with at least one previous glance, references how often participants' return to an AOI they have already viewed. Repeat-viewings of particular regions help both gather and update information for scene processing. This measure was used to determine what teachers' noticed and 
identified as important to the teaching situations (Van Es and Sherin 2002), and to identify where experts and novices monitored classroom information differently.

Number of Skips, in contrast to revisits, reports AOIs which were not viewed during the experiment, and is calculated as an AOI that did not register any fixations from a participant for the entirety of the video. To strengthen the identification of group differences in terms of skipped AOIs, we report only those areas where half or more of the expertise group did not fixate on the AOI. In terms of teachers' noticing, skips helped identify where experts and novices ignored classroom information and how they differed in terms of unviewed areas.

\section{Research question 3: verbal data}

Word usage of participants was analysed using specific lexical features of participants' verbalizations. Think aloud protocols were transcribed verbatim and analysed using the open-source textometry program TXM (version 0.7.5; http://textometrie.ens-lyon.fr/?lang= en). Textometry makes it possible to compare structural and semantic elements of word usage between individuals or groups by quantifying frequencies of linguistic features, such as lemmas. ${ }^{1}$ We quantified and compared lemma frequencies of mental/experiential and action/event/movement words to identify categorical differences between the two expertise groups. Using lemmas allowed us to capture participants' word usage frequencies for all forms of the selected word categories, regardless of grammatical inflection, such as tense or case. Word usage was used to identify underlying differences in how experts and novice teachers' used their contextual knowledge of problematic classroom scenes to notice activity and think about the classroom situations presented (Van Es and Sherin 2002).

As our analysis was exploratory, we sought basic yet meaningful differences in the way experts and novices expressed words related to cognitive and event processing. Recent research in the medical domain has shown that comparing frequencies of specific word categories is helpful for combining visual and cognitive perspectives and identifying expertise differences therein (Jaarsma et al. 2015). The theory of semantic primes describes a small set of words conveying meaning within languages, and which cannot be reduced to simpler terms or definitions (Drobnak 2009; Goddard 2002; Wierzbicka 1996). Semantic primes provided the basis for our word categories. To detect difference in words related to cognition and perception, we compared semantic primes frequencies related to mental/ perceptual words: think, know, want, see, hear, feel. To detect differences in attention to classroom events, we compared semantic prime frequencies related to action, event, and movement: do, happen, move.

In linguistic text analysis, these particular words selected for analysis can be broadly categorized as "content words" that convey the content and meaning of what is said. In our analysis, all of the semantic primes represent regular verbs defining "primary categories and actions dictated by the speaker" (Tausczik and Pennebaker 2010, p. 345). The mental/ perceptual semantic primes analysed can be more specifically categorized as verbs conveying "cognitive mechanisms", which are linked to more complex thinking and perceptual processing of information in the environment. The action/event words primes convey attention to events, activity, and movement.

\footnotetext{
1 A lemma is a lexical unit representing the set of all word forms sharing the same core meaning, e.g. the lemma go represents go, goes, going, went, gone (Knowles and Don 2004).
} 


\section{Results}

We applied a two-step analysis to eye movement measures. First, mixed-design repeated measures ANOVA repeated over type of video with expertise as the between-subjects factor were conducted on group means for three eye movement measures: fixation dispersion averages, total number of AOI revisits, total number of AOI skips. Then, to explore and identify between group differences per AOI, we calculated confidence intervals showing significant between-group differences for AOI revisits and skips for all 64 AOIs in the grid. Confidence intervals provide a range of values for the population mean of a given statistical sample by defining how probable it is that hypotheses derived from the distribution of the measured data are true (Field 2009).

\section{Research question 1: focused viewing}

\section{Fixation dispersion}

Statistical analysis with a mixed-design ANOVA showed a main effect for expertise with 'fixation dispersion average', $F(1,60)=6.04, p=0.017, \eta^{2}=0.10$. Novices' fixations were significantly more dispersed than experts, meaning that experts' fixations were more focused while viewing the videos. There was no significant effect for the type of video, $F(1,60)=2.32, p=0.133, \eta^{2}=0.04$, and there was no interaction effect for video and expertise, $F(1,60)=1.38, p=0.245, \eta^{2}=0.02$.

\section{Research question 2a: monitored areas}

Step 1 Mixed-design repeated measures ANOVA Between subject-effects showed no significance expertise differences for the total amount of AOI revisits, $F(1$, $60)=3.187, p=0.079, \eta^{2}=0.05$. There was a significant effect for the type of video shown, $F(1,60)=15.14, p<0.001, \eta^{2}=0.20$, with Type 2 videos (Video 3; Video 4) receiving more revisits than Type 1 videos(Video 1; Video 2). Thus, Type 2 videos showed blatant, escalating disruptions warranting more frequent monitoring. There was no interaction effect for video type and expertise, $F<1$.

See Table 1 for means and standard deviations per video

Step 2 Confidence intervals To reduce the instance of Type II errors, we only report confidence intervals of $99 \%$ or higher. Refer to Tables 3 and 6 in the appendix for an overview of the significant between-group differences per AOI for revisits and skips

Experts revisited, or monitored, more areas than novices in all four videos. In both video types, novices revisited AOIs showing limited or no classroom activity (i.e. walls, paintings, a bright window showing hallway activity). Experts appear to be searching for activity between students and following posture and body movements, while novices returned more often to areas showing little or no student activity. For example, novices monitored an area showing the leg of a fidgety student wearing fluorescent green shoelaces that appear to be an image-driven attractor for the novice group. Contrastively, experts returned more often to areas showing students and classroom activity. These areas displayed students' shoulders, chests, arms, elbows, hands, their desktops, and occasionally their legs. When experts revisited AOIs showing faces, these AOIs generally show multiple 
Table 1 Means and standard deviations for eye movement measures (per video)

\begin{tabular}{llll}
\hline Measure & \multicolumn{2}{l}{ Expertise } & \\
\cline { 2 - 4 } & Experts & Novices & Total \\
\hline $\mathrm{N}$ & 30 & 32 & 62 \\
Fixation dispersion average & & & $81.29(53.33)$ \\
Video 1: Type 1, Class 1 & $68.69(17.32)$ & $93.10(70.84)$ & $73.83(23.27)$ \\
Video 2: Type 1, Class 2 & $67.02(18.28)$ & $80.21(25.80)$ & $84.36(47.19)$ \\
Video 3: Type 2, Class 1 & $68.34(17.43)$ & $99.38(60.14)$ & $76.58(26.77)$ \\
Video 4: Type 2, Class 2 & $68.69(22.32)$ & $83.98(28.76)$ & $528.19(197.59)$ \\
AOI revisits & & & $374.18(130.67)$ \\
Video 1: Type 1, Class 1 & $562.10(181.07)$ & $496.41(209.76)$ & $376.71(135.38)$ \\
Video 2: Type 1, Class 2 & $406.50(128.36)$ & $343.88(127.37)$ & $623.01(272.51)$ \\
Video 3: Type 2, Class 1 & $413.17(129.99)$ & $342.53(133.28)$ & \\
Video 4: Type 2, Class 2 & $673.32(273.65)$ & $575.84(267.07)$ & $33.79(4.34)$ \\
AOI skips & & & $37.93(3.83)$ \\
Video 1: Type 1, Class 1 & $33.30(4.44)$ & $34.25(4.27)$ & $39.47(3.62)$ \\
Video 2: Type 1, Class 2 & $36.97(3.25)$ & $38.84(4.15)$ & $37.02(5.12)$ \\
Video 3: Type 2, Class 1 & $39.43(3.79)$ & $39.50(3.51)$ & $38.09(5.77)$ \\
Video 4: Type 2, Class 2 & $35.87(4.13)$ & & \\
\hline
\end{tabular}

students in the AOI, including interactive regions between different rows of students. In sum, experts revisited more areas showing physical and verbal interactions of or between students, while novices revisited more regions lacking classroom interactions. See Tables 3 and 4 for details on the AOIs showing significantly more revisits per expertise group (Fig. 2).

\section{Research question 2b: skipped areas}

Step 1 Mixed-design repeated measures ANOVA No expertise effects were found in the number of AOI skips per expertise group, $F(1,60)=2.71, p=0.105$, $\eta^{2}=0.04$. There was a significant effect for the type of video shown, $F(1$, $60)=25.21, p<0.001, \eta^{2}=0.30$, with Type 1 videos (Video 1 ; Video 2) showing more skips than Type 2 videos (Video 3; Video 4). There was no interaction effect for video type and expertise, $F<1$. Type 1 videos showed unrelated, subtle classroom events with no particular localized problems, leading to more areas being skipped. In contrast, Type 2 videos showed interrelated, problematic events spreading over the classroom, leading to fewer areas being skipped (Fig. 3).

Step 2 Confidence intervals In all four videos, novices skipped more AOIs than experts, meaning half or more of the novices viewing the videos never looked at these areas. There were no instances where the majority of experts skipped more AOIs. Novices, on the other hand, skipped areas showing students, interactions between groups of students, desk surfaces, and empty spaces between rows of students. In general, it appears that novices are consistently missing areas that 


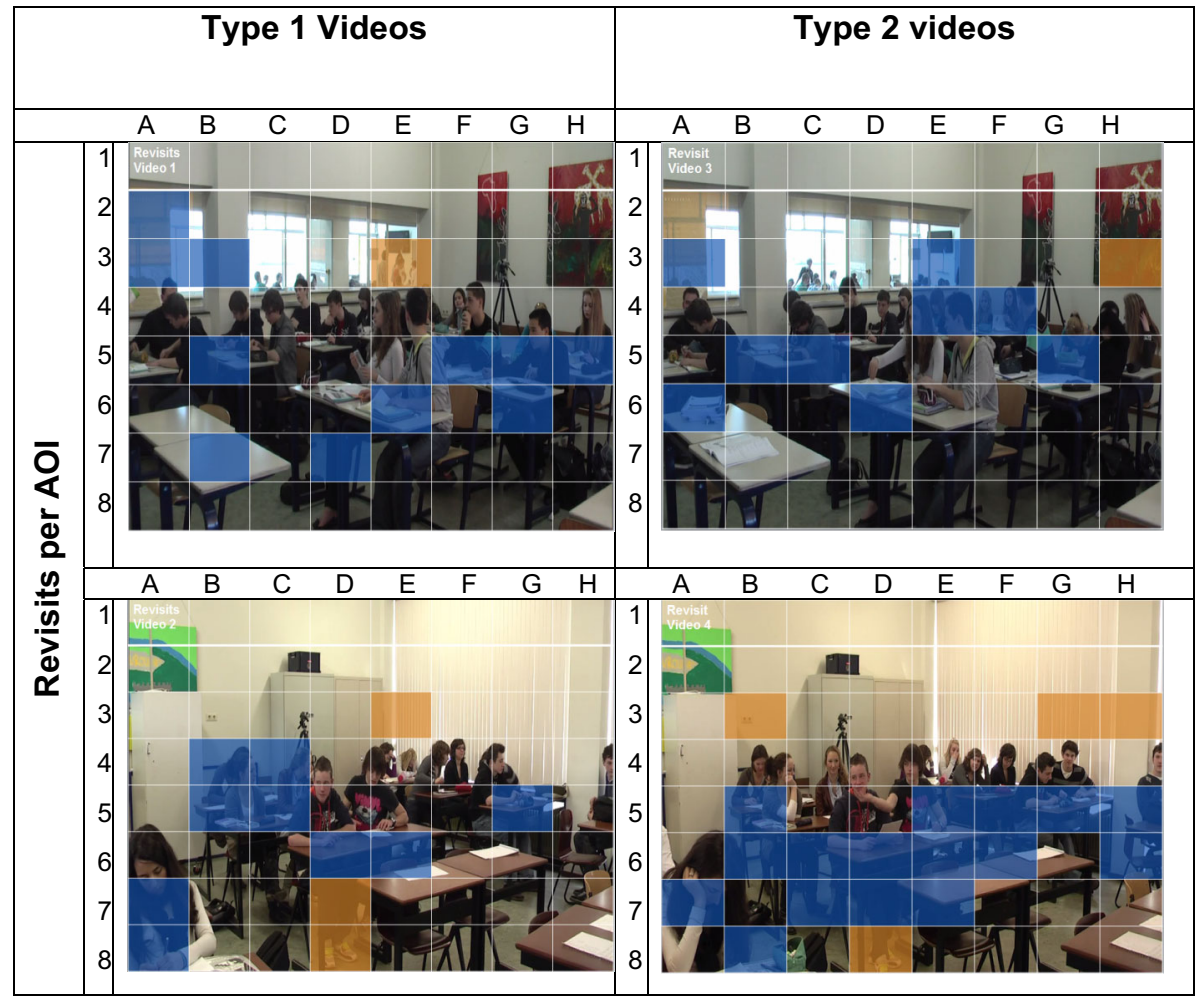

Fig. 2 Stills comparing revisits: areas in the classroom repeatedly monitored by experts and novices. Note: Blue grids denote significantly more revisits from experts, orange grids from novices. To locate specific AOIs, columns are identified by letters and rows are identified by numbers. (Color figure online)

experts are viewing. See Tables 5 and 6 for details on the number of AOIs showing significantly more skips per expertise group.

\section{Research question 3: word usage}

Chi square tests are used to measure associations and compare frequencies observed in different data categories (Field 2009). We compared the occurrence of specific semantic primes per level of teaching expertise. There was a significant association between experience and word usage, $\chi^{2}(8, N=937)=30.45, p<0.001$. Teaching experience was associated with higher frequency of both mental/perceptual and action/event word categories, suggesting more complex thinking, perceptual processing, and attention to classroom events on the part of experts.

Expert teachers used the action/event word 'happen' significantly more, $(N=58$, versus 43.8 expected, $z=2.1, p<0.001$ ), whereas novices used it less ( $N=16$, vs. 30.2 expected, $z=-2.6, p<0.001)$. That is, experts expressed more words related to action/ event processing. See Table 2 for the percentages of word frequencies. 


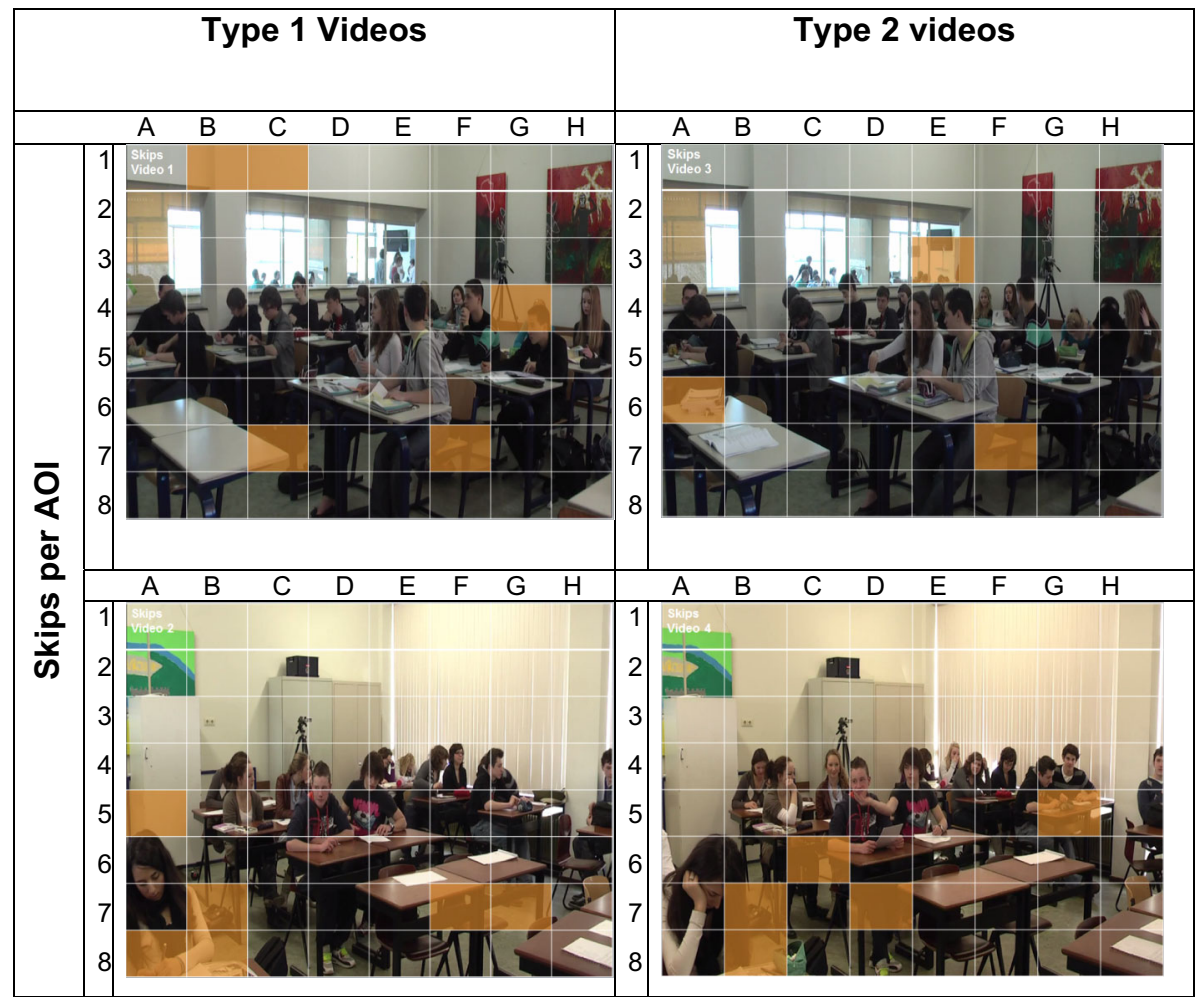

Fig. 3 Stills comparing areas experts and novices teachers skipped while viewing classroom videos. Note: Orange grids show areas skipped significantly more by novices; the expert group did not have significantly more skips. To locate specific AOIs, columns are identified by letters and rows are identified by numbers. (Color figure online)

\section{Discussion}

This study investigated the question of how experts and novice teachers differ in their visual processing of the classroom. We considered multiple ways in which teachers' perceptual processing allows teachers to interpret cues, events, and interactions occurring in problematic classroom scenes. We compared elements of expert and novice teachers' visual processing to determine (1) how distributed a particular expertise group's fixations were; and (2) which areas and features were repeatedly monitored and which were skipped in the search for classroom information. We also compared teachers' think aloud verbalizations to determine (3) how experts and novices differed in terms of word usage linked to cognition, perception, actions, and events.

\section{Research question 1}

Consistent with research conducted in other professional domains, we found that teaching experience directly related to significant main effects of fixation dispersion across all videos, irrespective of the types of classroom problems depicted. As a group, experts fixations were less spread out (i.e. more focused) than novices, suggesting efficient 
Table 2 Percentage of semantic primes per word categories and expertise group

\begin{tabular}{|c|c|c|c|}
\hline Semantic prime & Total & Experts & Novices \\
\hline \multicolumn{4}{|l|}{ Type 1 Videos } \\
\hline \multicolumn{4}{|c|}{ Mental/perceptual processing words } \\
\hline Think & 117 & $52 \%$ & $48 \%$ \\
\hline Know & 150 & $48 \%$ & $52 \%$ \\
\hline Want & 49 & $69 \%$ & $31 \%$ \\
\hline See & 212 & $58 \%$ & $42 \%$ \\
\hline Hear & 31 & $65 \%$ & $35 \%$ \\
\hline Feel & 9 & $100 \%$ & 0 \\
\hline \multicolumn{4}{|c|}{ Actions/event/movement processing words } \\
\hline Do & 287 & $60 \%$ & $40 \%$ \\
\hline Happen & 74 & $78 \%$ & $22 \%$ \\
\hline Move & 8 & $63 \%$ & $37 \%$ \\
\hline \multicolumn{4}{|l|}{ Type 2 Videos } \\
\hline \multicolumn{4}{|c|}{ Mental/perceptual processing words } \\
\hline Think & 123 & $63 \%$ & $37 \%$ \\
\hline Know & 108 & $48 \%$ & $52 \%$ \\
\hline Want & 63 & $75 \%$ & $25 \%$ \\
\hline See & 220 & $54 \%$ & $46 \%$ \\
\hline Hear & 29 & $52 \%$ & $48 \%$ \\
\hline Feel & 10 & $90 \%$ & $10 \%$ \\
\hline \multicolumn{4}{|c|}{ Actions/event/movement processing words } \\
\hline Do & 298 & $51 \%$ & $49 \%$ \\
\hline Happen & 83 & $70 \%$ & $30 \%$ \\
\hline Move & 10 & $90 \%$ & $10 \%$ \\
\hline
\end{tabular}

perceptual encoding of the available visual information and supporting the idea that experts chunk the visual information into meaningful units which serve to guide and focus their search (Reingold and Sheridan 2011). Novices' fixations were more dispersed, and their viewing, overall, appeared to be less selective and discriminating than that of experts.

van den Bogert et al. (2014) concluded that pre-service teachers' event-noticing draws their fixation towards a single event at the expense of noticing other events in the classroom. They did not, however, consider the extent to which teachers fixations were focused or dispersed. Our finding suggests that novices do actually distribute their fixations across the expanse of the classroom, but they are not attending to the same range of meaningful cues and events as experts due to the scattered, less-focused spread of their fixations.

\section{Research question 2}

Experts consistently had more repeat fixations to specific, concentrated areas than novices did in all videos. Revisit results offer a configuration which is rather stable for both expertise groups. Novices exclusively revisited more AOIs void of discernible student activity, whereas experts were inclined to monitor AOIs showing students' body parts, such as trunks, shoulders, arms, elbows, and hands, and occasionally faces (where human attention is typically drawn). In these AOIs, many interactions and movements between students are also present. 
Particularly in Video 3 and Video 4, these activities escalate into the most disruptive students unmistakably distracting adjacent students by throwing spit balls across the room, by waving their arms repeatedly at a student outside the classroom and taking away the papers that neighbouring students are working with. Experts' monitoring in these blatantly disruptive scenes do not fixate most frequently on the students creating such distractions, but rather on the surrounding students. They appear to be viewing the effects of disruptions on groups of students situated elsewhere in the classroom. These patterns suggest that experts' monitoring is guided by knowledge of how problematic situations can influence students on the periphery of problematic behaviour. In other words, experts' knowledge about classroom disruptions and how they evolve seems to drive their monitoring of events, students, and interactions. Novices' monitoring, on the other hand, suggests an image-driven pattern with a narrower field of vision (for example, revisiting an AOI showing sneakers with fluorescent shoelaces). We link novices' constrained ability to detect and monitor informative, interactive areas to a lack of experience and event-based professional knowledge that helps overcome the tendency to return to visually salient yet uninformative areas of the class. Novices' monitoring seems to be guided more by the location of disruptions and other salient features, such as bright colours.

Experts' revisits cover an extended field of vision, alluding to a professional skill of selectively focusing on areas containing informative cues for continually monitoring classroom events. Our claim is that experts have learned through experience to pass over disingenuous cues, and instead seek subtle but consequential cues conveyed via students' posture, physical movements, and discreetly suggestive behaviour. They monitor such areas attentively because they have learned over time to be more discriminating, and have developed a perceptive professional sensitivity to less conspicuous physical and interactional cues (Sherin 2001; Westerman 1991).

Concerning skipped areas, the novice group skipped more AOIs than experts in every video, and in some cases they skipped the same areas that experts frequently revisited. These findings align with general features of professional expertise, namely that experts detect and focus on features that novices miss (Chi 2006). It also suggests that experts' classroom and event knowledge makes them capable of passing over irrelevant information in classroom scenes because they have learned to systematically reduce the kinds of information that should be sought after (Doyle 1990). They can devote more attention to informative areas, whereas novices lack the experience and knowledge to do so. (Haider and Frensch 1996). Novices' less discriminate search for information causes them to skip areas presenting cues and events that experts deem informative and worthy of continued monitoring. Not knowing where to look, novices skip more areas of the classroom and fixate more on salient features of the image (in this case, the videos).

\section{Research question 3}

In both types of classroom management scenes, experts more frequently used mental/perceptual words associated with complex thinking styles and also employed words denoting actions and events more frequently (Pennebaker 2011; Wierzbicka 1996). We take this to mean that their thoughts are organized closely with their sensorial perception ('see'; 'hear') and their experiential knowledge and expectations of classrooms ('think'; 'want') in relation to the actions and events taking place in the video ('do'; 'happen'; 'move'). However, deeper analysis of teachers' verbalizations is required to draw specific conclusions as to how teachers' knowledge influences expert-novice differences concerning what is noticed and how these perceptions affect interpretations of classroom management events. 
Results from our analysis of basic differences in the words used by experts and novices offers supplemental support to the hypothesis that experts' knowledge about classroom problems and events drives their visual processing. It aligns with research showing that experts' have richer stores of knowledge about classrooms and students than novices, allowing them to verbalize visual processing in a more complex manner (Carter et al. 1988). The content of experts' verbalizations used more words conveying complex thinking and perceptual processing, as well as attention to events. Novices' emerging knowledge of classroom events hinders their ability to recognize relevant information as they process classroom scenes, resulting in less complex thinking about events and problems in the classroom. When representing classroom management events, novices' management focus is often framed around issues of behaviour and discipline from their own point of view. Experts' knowledge allows them to: focus on actions and events themed around student learning, consider management concerns from multiple points of view (their own, that of students, and that of another teacher), predict problems before they intensify, and keep track of the continuity of classroom events and interactions (Wolff et al. 2015).

\section{Limitations}

While our exploratory analysis of teachers' eye movements confirms that experience plays an important role in teachers' perception of classroom cues, it only does so in a general way. We found significant differences between expertise groups as a whole. Exploring within-group differences may provide further insights into how teachers' visual processing develops and differs amongst beginner and experienced teachers. Similarly, contrasting results from differently-sized AOI grids, particularly smaller grids, could yield interesting result both between and within expertise groups. This study grouped teachers based on their level of expertise, and did not explore potential differences based on teachers' subject domains. However, identifying whether or not differences exist across different subjects could be an interesting investigation for future research into teachers' perceptions. Additionally, considering how age may affect teachers' visual processing also warrants further investigation, as this study considered the influence of years of teaching experience on classroom perceptions without considering biological age.

Although we contrasted different types of problematic classroom situations, our study sheds no light upon expert-novices differences in non-problematic situations. The inclusion of smoothly executed, dynamic classroom management scenes in future research could offer insights for distinguishing effective from ineffective management. Also, our concentration on visual processing furthered understanding of teachers' perception, but it would be interesting to further explore the link between perceptual and interpretative cognitive processing. Identifying the cues, actors, events, and conceptualizations of classroom management teachers consider most meaningful may help improve models of teacher cognition and explain both convergences and divergences in teachers' thinking (Colestock and Sherin 2009).

\section{Conclusions}

Expertise differences in fixation dispersion as well as the grid analysis can be read as an indication that experts and novices recognize different visual cues as being important to classroom management. Experts' experience-based, event-structured knowledge allows 
them to derive meaning from these cues differently than novices. Such knowledge drives focused observational strategies to selectively seek out and monitor specific visual cues informing the interpretation of events. In the case of teachers, it allows experts to notice patterns and selectively attend to potentially important cues and events for classroom management before they become pronounced, and it directs their continual monitoring of the classroom.

The key issue behind managing problematic classroom management may not be a strict question of whether or not a teacher sees an event and has access to the requisite relevant information, but more a matter of how they notice what they are observing and recognize what it means for teaching practice. Van Es and Sherin (2002) define three central elements of teachers' noticing: (1) identifying what is important about the teaching situation; (2) relating the specific classroom interactions to the larger principles of teaching and learning that they represent; and (3) using knowledge about context to reason about the classroom interactions that are noticed. Copeland et al. (1994) suggest that an ability to articulate a clear sense of educational purpose may also guide attention as teachers notice, interpret, and process classrooms. Perhaps novices lack more than just integrated, visual processing supported by knowledge and experience to generate pedagogically-sound classroom management skills for facilitating student learning. They also lack contextualized, purposeful, practice-oriented event knowledge to selectively guide their attention to the kinds of cues and classroom events that need to be noticed in the first place. Such pedagogical knowledge gaps make it difficult for novices to interpret and monitor relevant cues. It may also explain why novices instead continue indiscriminately searching all over the classroom for any information that could be construed as potentially relevant, and why they miss features that experts continually monitor (Berliner 2001; Boshuizen and Schmidt 2008; Carter et al. 1988).

Our findings add new insights into teachers' visual processing, emphasizing the link between teacher expertise, visual processing and awareness for classroom management. While this study shows several ways in which knowledge guides teachers' withitness as they process the complex array of problematic events that arise in classrooms, many aspects of teachers' processing remain unclear. The contours of teachers' visual processing are emerging, but research clarifying the developmental link between teachers' vision and event knowledge, and how teaching experience transforms the pedagogical knowledge applied to classroom management remains to be seen.

Acknowledgments The authors are grateful for the cooperation and participation of the school directors, teachers, and pre-service teachers from the various Dutch institutions that contributed their time and knowledge to the execution of this study. We thank Dr. Frank Crasborn for his vital role in school and participant recruitment. Additional thanks to Dr. Peter Delmont for his assistance with the confidence interval analysis and to the TXM team at École Normale Supériere de Lyon at the University of Lyon for their support during textometry analysis.

Open Access This article is distributed under the terms of the Creative Commons Attribution 4.0 International License (http://creativecommons.org/licenses/by/4.0/), which permits unrestricted use, distribution, and reproduction in any medium, provided you give appropriate credit to the original author(s) and the source, provide a link to the Creative Commons license, and indicate if changes were made.

\section{Appendix}

See Appendix Tables 3, 4, 5 and 6. 
Table 3 Confidence intervals showing significant differences for AOI revisits in Type 1 videos

\begin{tabular}{|c|c|c|c|}
\hline \multirow{31}{*}{$\begin{array}{l}\text { Table } 3 \text { Confidence intervals } \\
\text { showing significant differences } \\
\text { for AOI revisits in Type } 1 \text { videos }\end{array}$} & AOI & $M(S D)$ & $99 \% \mathrm{CI}$ \\
\hline & Video 1 & & \\
\hline & Experts & & \\
\hline & $\mathrm{A} 2$ & $69.3(19.3)$ & $(31.4,107.2)$ \\
\hline & A3 & $84.3(17.2)$ & $(50.6,118.0)$ \\
\hline & A5 & $229.8(44.6)$ & $(142.4,317.2)$ \\
\hline & B3 & $55.2(17.3)$ & $(21.4,89.0)$ \\
\hline & B5 & $462.3(65.5)$ & $(333.9,590.7)$ \\
\hline & B7 & $22.5(8.9)$ & $(5.0,40.0)$ \\
\hline & D7 & $2.7(2.9)$ & $(-2.9,8.4)$ \\
\hline & E6 & $163.2(29.1)$ & $(106.2,220.2)$ \\
\hline & G5 & $499.8(62.7)$ & $(376.9,622.7)$ \\
\hline & G6 & $39.3(13.1)$ & $(13.6,65.0)$ \\
\hline & H5 & $76.8(26.3)$ & $(0.00,76.8)$ \\
\hline & Novices & & \\
\hline & E3 & 170.7 (46.6) & $(79.3,262.1)$ \\
\hline & Video 2 & & \\
\hline & Experts & & \\
\hline & A7 & 95.7 (23.7) & $(49.3,142.1)$ \\
\hline & A8 & $1.8(1.9)$ & $(-1.9,5.6)$ \\
\hline & B4 & $131.4(29.6)$ & $(73.3,189.5)$ \\
\hline & B5 & $122.7(23.1)$ & $(77.5,167.9)$ \\
\hline & $\mathrm{C} 4$ & $448.2(52.5)$ & $(345.3,551.2)$ \\
\hline & $\mathrm{C} 5$ & $506.4(78.1)$ & $(353.3,659.5)$ \\
\hline & D6 & $219.3(42.7)$ & $(135.7,302.9)$ \\
\hline & E6 & $123.9(31.5)$ & $(62.1,185.7)$ \\
\hline & G5 & $174.0(333.9)$ & $(227.4,440.4)$ \\
\hline & Novices & & \\
\hline & D7 & & $(2.3,46.3)$ \\
\hline & D8 & & $(-2.78,34.6)$ \\
\hline & E3 & & $(-5.4,138.6)$ \\
\hline \multirow{11}{*}{$\begin{array}{l}\text { Table } 4 \text { Confidence intervals } \\
\text { showing significant differences } \\
\text { for AOI revisits in Type } 2 \text { videos }\end{array}$} & AOI & $M(S D)$ & $99 \% \mathrm{CI}$ \\
\hline & Video 3 & & \\
\hline & Experts & & \\
\hline & $\mathrm{A} 3$ & $23.4(8.8)$ & $(6.2,40.6)$ \\
\hline & A6 & $5.7(4.3)$ & $(-2.7,14.1)$ \\
\hline & B5 & $249.3(44.0)$ & $(163.1,335.5)$ \\
\hline & C5 & $195.9(37.4)$ & $(122.7,269.1)$ \\
\hline & D6 & $64.8(16.6)$ & $(32.3,97.3)$ \\
\hline & E3 & $37.5(15.1)$ & $(8.0,67.0)$ \\
\hline & E4 & $1128.9(102.2)$ & $(928.7,1329.1)$ \\
\hline & $\mathrm{F} 4$ & $1793.4(162.0)$ & $(1475.9,2111.0)$ \\
\hline
\end{tabular}


Table 4 continued

$C I$ confidence interval

Table 5 Confidence intervals showing significant differences for AOI skips in Type 1 videos

\begin{tabular}{|c|c|c|}
\hline AOI & $M(S D)$ & $99 \% \mathrm{CI}$ \\
\hline G5 & $387.3(51.4)$ & $(286.5,488.1)$ \\
\hline \multicolumn{3}{|c|}{ Novices } \\
\hline H3 & 24.3 (11.4) & $(1.9,46.7)$ \\
\hline \multicolumn{3}{|c|}{ Video 4} \\
\hline \multicolumn{3}{|c|}{ Experts } \\
\hline A7 & $52.5(15.1)$ & $(22.9,82.1)$ \\
\hline B5 & $254.1(50.5)$ & $(192.4,499.4)$ \\
\hline B6 & $141.6(21.4)$ & $(99.6,183.6)$ \\
\hline B8 & $10.2(6.1)$ & $(-1.8,22.2)$ \\
\hline C6 & $51.6(16.9)$ & $(18.5,84.7)$ \\
\hline $\mathrm{C} 7$ & $2.7(2.9)$ & $(-2.9,8.4)$ \\
\hline D6 & $289.8(52.2)$ & $(187.5,392.1)$ \\
\hline D7 & $5.7(4.1)$ & $(-2.2,13.6)$ \\
\hline E5 & $1231.8(179.7)$ & $(879.7,1583.9)$ \\
\hline E6 & $185.7(36.9)$ & $(113.4,258.1)$ \\
\hline E7 & $2.7(2.9)$ & $(-3.00,8.4)$ \\
\hline F5 & $565.2(117.3)$ & $(335.4,795.0)$ \\
\hline F6 & $52.5(13.4)$ & $(26.3,78.7)$ \\
\hline G5 & $479.1(110.4)$ & $(262.7,695.5)$ \\
\hline H5 & $147.3(38.6)$ & $(71.6,223.0)$ \\
\hline H6 & $30.0(16.5)$ & $(-2.3,62.3)$ \\
\hline \multicolumn{3}{|c|}{ Novices } \\
\hline B3 & $19.8(12.7)$ & $(-4.9,49.6)$ \\
\hline D8 & $11.4(7.5)$ & $(-3.2,26.0)$ \\
\hline G3 & $70.2(30.5)$ & $(10.5,129.9)$ \\
\hline H3 & $54.3(19.9)$ & $(15.3,93.3)$ \\
\hline
\end{tabular}

\begin{tabular}{|c|c|c|}
\hline AOI & $M(S D)$ & $99 \% \mathrm{CI}$ \\
\hline
\end{tabular}

Video 1

Novices

B1

$28.2(1.4)$

(25.5, 30.9)

C1

$29.1(0.9)$

(27.2, 31.0)

(27.2, 31.0)

$(25.5,30.9)$

F7

$29.1(0.9)$

(13.6, 24.2)

$\mathrm{H} 4$

$28.2(1.4)$

18.9 (2.7)

Video 2

Novices

$\begin{array}{lll}\text { A5 } & 26.4(1.9) & (22.8,30.1) \\ \text { A8 } & 24.3(2.2) & (20.0,28.6) \\ \text { B7 } & 18.9(2.7) & (13.6,24.2) \\ \text { B8 } & 16.8(2.7) & (11.4,22.2) \\ \text { F7 } & 27.3(1.6) & (24.1,30.5) \\ \text { G7 } & 28.2(1.4) & (25.5,30.9)\end{array}$

CI confidence interval 
Table 6 Confidence intervals showing significant differences for AOI skips in Type 2 videos

\begin{tabular}{cll}
\hline AOI & $M(S D)$ & $99 \% \mathrm{CI}$ \\
\hline Video 3 & & \\
Novices & & \\
A6 & $24.3(2.2)$ & $(20.0,28.6)$ \\
E3 & $26.4(1.9)$ & $(22.8,19.6)$ \\
F7 & $28.2(30.1)$ & $(25.5,30.9)$ \\
Video 4 & & \\
Novices & & \\
B7 & $16.8(2.7)$ & $(11.4,22.2)$ \\
B8 & $19.8(2.6)$ & $(14.7,25.0)$ \\
C6 & $13.2(2.7)$ & $(21.2,29.2)$ \\
D7 & $25.2(2.0)$ & $(8.6,19.6)$ \\
G5 & $14.1(2.8)$ & \\
\hline
\end{tabular}

CI confidence interval

\section{References}

Behets, D. (1996). Comparison of visual information processing between preservice students and experienced physical education teachers. Journal of Teaching in Physical Education, 16, 79-87.

Berliner, D. (2001). Learning about and learning from expert teachers. International Journal of Educational Research, 35(5), 463-482. doi:10.1016/S0883-0355(02)00004-6.

Berliner, D. (2004). Describing the behavior and documenting the accomplishments of expert teachers. Bulletin of Science, Technology \& Society, 24(3), 200-214.

Boshuizen, H. P. A. (2009). Teaching for expertise: Problem-based methods in medicine and other professional domains. In K. A. Ericsson (Ed.), Development of professional expertise: Toward measurement of expert performance and design of optimal learning environments (pp. 379-404). New York: Cambridge University Press.

Boshuizen, H. P. A., \& Schmidt, H. G. (2008). The development of clinical reasoning expertise; Implications for teaching. In J. Higgs, M. Jones, S. Loftus, \& N. Christensen (Eds.), Clinical reasoning in the health professions (3rd ed., pp. 113-121). Oxford: Butterworth-Heineman/Elsevier.

Brophy, J. (1999). Perspectives of classroom management: Yesterday, today, and tomorrow. In J. H. Freiberg (Ed.), Beyond behaviorism: Changing the classroom management paradigm (pp. 43-56). Boston: Allyn and Bacon.

Carter, K., Cushing, K., Sabers, D., Stein, P., \& Berliner, D. (1988). Expert-novice differences in perceiving and processing visual classroom information. Journal of Teacher Education, 39(3), 25-31. doi:10. $1177 / 002248718803900306$.

Carter, K., Doyle, H., \& Doyle, H. W. (1987). Teachers' knowledge structures and comprehension processes. In J. Calderhead (Ed.), Exploring teachers' thinking (pp. 147-160). London: Cassell.

Chi, M. (2006). Two approaches to the study of experts' characteristics. In K. A. Ericsson, N. Charness, P. Feltovich, \& R. Hoffman (Eds.), The Cambridge handbook of expertise and expert performance (pp. 21-30). New York: Cambridge University Press.

Colestock, A., \& Sherin, M. G. (2009). Teachers' sense-making strategies while watching video of mathematics instruction. Journal of Technology and Teacher Education, 17(1), 7-29.

Copeland, W. D., Birmingham, C., DeMeulle, L., D’Emidio-Caston, M., \& Natal, D. (1994). Making meaning in classrooms: An investigation of cognitive processes in aspiring teachers, experienced teachers, and their peers. American Educational Research Journal, 31(1), 166-196. doi:10.3102/ 00028312031001166.

Doyle, W. (1977). Learning the classroom environment: An ecological analysis of induction into teaching. In Annual Meeting of the American Educational Research Association. New York: American Educational Research Association.

Doyle, W. (1990). Classroom knowledge as a foundation of teaching. Teachers College Record, 91(3), 347-360. 
Doyle, W. (2006). Ecological approaches to classroom management. In C. Evertson \& C. Weinstein (Eds.), Handbook of classroom management: Research, practice and contemporary issues (pp. 97-125). Mahweh, NJ: Lawrence Erlbaum Associates.

Drobnak, F. T. (2009). On the merits and shortcomings of semantic primes and natural semantic metalanguage in cross-cultural translation. In S. Komar \& U. Mozetič (Eds.), As you write it: Issues in literature, language, and translation in the context of Europe in the 21st century II (pp. 29-41). Slovenia: Slovene Association for the Study of English.

Ericsson, K. A., \& Simon, H. A. (1980). Verbal reports as data. Psychological Review, 87(3), $215-251$. doi: 10.1037/0033-295X.87.3.215.

Evertson, C., \& Weinstein, C. (2006). Classroom management as a field of inquiry. In C. Evertson \& C. Weinstein (Eds.), Handbook of classroom management: Research, practice and contemporary issues (pp. 3-16). Mahweh, NJ: Lawrence Erlbaum Associates.

Field, A. (2009). Discovering statistics using SPSS. London: Sage.

Goddard, C. (2002). The search for the semantic core of all languages. In C. Goddard \& A. Wierzbicka (Eds.), Meaning and universal grammar-theory and empirical findings (Vol. I, pp. 5-40). Amsterdam: John Benjamins.

Goodwin, C. (1994). Professional vision. American Anthropologist, 96(3), 606-633.

Haider, H., \& Frensch, P. A. (1996). The role of information reduction in skill acquisition. Cognitive Psychology, 30(3), 304-337. doi:10.1006/cogp.1996.0009.

Hattie, J. (2003, October). Teachers make a difference: What is the research evidence? Paper presented at the Australian Council for Educational Research Annual Conference on Building Teacher Quality, Melbourne, Victoria, Australia.

Hattie, J. (2012). Visible learning for teachers: Maximizing impact on learning. New York: Routledge.

Henderson, J. (2011). Eye movements and scene perception. In S. Liversedge, I. Gilchrist, \& S. Everling (Eds.), The Oxford handbook of eye movements (pp. 593-606). Oxford: Oxford University Press.

Hogan, T., Rabinowitz, M., \& Craven, J, I. I. I. (2003). Representation in teaching: Inferences from research of expert and novice teachers. Educational Psychologist, 38(4), 235-247.

Holmqvist, K., Nystrom, M., Andersson, R., Dewhurst, R., Jarodzka, H., \& van de Weijer, J. (2011). Eye tracking: A comprehensive guide to methods and measures. Oxford: Oxford University Press.

Itti, L., \& Koch, C. (2000). A saliency-based search mechanism for overt and covert shifts of visual attention. Vision Research, 40, 1489-1506.

Jaarsma, T., Jarodzka, H., Nap, M., van Merriënboer, J. J. G., \& Boshuizen, H. P. A. (2015). Expertise in clinical pathology: Combining the visual and cognitive perspective. Advances in Health Sciences Education, 20(4), 1089-1106. doi:10.1007/s10459-015-9589-x.

Just, M., \& Carpenter, P. (1976). Eye fixations and cognitive processes. Cognitive Psychology, 8(4), 441-480. doi:10.1016/0010-0285(76)90015-3.

Knowles, G., \& Don, Z. M. (2004). The notion of a "lemma": Headwords, roots, and lexical sets. International Journal of Corpus Linguistics, 9(1), 69-81.

Kounin, J. (1970). Discipline and group management in classrooms. New York: Rinehart and Winston.

Kunter, M., Klusmann, U., Baumert, J., Richter, D., Voss, T., \& Hachfeld, A. (2013). Professional competence of teachers: Effects on instructional quality and student development. Journal of Educational Psychology, 105(3), 805-820. doi:10.1037/a0032583.

Lesgold, A., Rubinson, H., Feltovich, P., Glaser, R., Klopfer, D., \& Wang, Y. (1988). Expertise in a complex skill: Diagnosing x-ray pictures. In M. Chi, R. Glaser, \& M. Farr (Eds.), The nature of expertise (pp. 311-342). Hillsdale, NJ: Erlbaum.

Livingston, C., \& Borko, H. (1989). Expert-novice differences in teaching: A cognitive analysis and implications for teacher education. Journal of Teacher Education, 40, 36-42. doi:10.1177/ 002248718904000407

Palmer, D., Stough, L., Burdenski, T, Jr, \& Gonzales, M. (2005). Identifying teacher expertise: An examination of researchers' decision making. Educational Psychologist, 40, 13-25.

Pennebaker, J. W. (2011). The secret life of pronouns: What our words say about us (1st U.S. ed). New York: Bloomsbury Press.

Rayner, K. (2009). Eye movements and attention in reading, scene perception, and visual search. The Quarterly Journal of Experimental Psychology, 62(8), 1457-1506. doi:10.1080/17470210902816461.

Reingold, E., \& Sheridan, H. (2011). Eye movements and visual expertise in chess and medicine. In S. Liversedge, I. Gilchrist, \& S. Everling (Eds.), The Oxford handbook of eye movements (pp. 523-550). Oxford: Oxford University Press.

Rink, J. E., French, K., Lee, A. M., Solmon, A., \& Lynn, S. K. (1994). A comparison of pedagogical knowledge structures of preservice students and teacher educators in two institutions. Journal of Teaching in Physical Education, 13, 140-162. 
Sabers, D., Cushing, K., \& Berliner, D. (1991). Differences among teachers in a task characterized by simultaneity, multidimensionality, and immediacy. American Educational Research Journal, 28(1), 63-88.

Sherin, M. (2001). Developing a professional vision of classroom events. In T. Wood, B. Nelson, \& J. Warfield (Eds.), Beyond classical pedagogy: Teaching elementary school mathematics (pp. 75-93). Mahweh, NJ: Erlbaum Associates.

Tausczik, Y. R., \& Pennebaker, J. W. (2010). The Psychological meaning of words: LIWC and computerized text analysis methods. Journal of Language and Social Psychology, 29(1), 24-54. doi:10.1177/ $0261927 X 09351676$.

Tsui, A. (2003). Understanding expertise in teaching: Case studies of second language teachers. Cambridge: Cambridge University Press.

van den Bogert, N., van Bruggen, J., Kostons, D., \& Jochems, W. (2014). First steps into understanding teachers' visual perception of classroom events. Teaching and Teacher Education, 37, 208-216. doi:10.1016/j.tate.2013.09.001.

Van Es, E. A., \& Sherin, M. G. (2002). Learning to notice: Scaffolding new teachers' interpretations of classroom interactions. Journal of Technology and Teacher Education, 10(4), 571-596.

van Meeuwen, L. W., Jarodzka, H., Brand-Gruwel, S., Kirschner, P. A., de Bock, J. J. P. R., \& van Merriënboer, J. J. G. (2014). Identification of effective visual problem solving strategies in a complex visual domain. Learning and Instruction, 32, 10-21. doi:10.1016/j.learninstruc.2014.01.004.

Westerman, D. A. (1991). Expert and novice teacher decision making. Journal of Teacher Education, 42(4), 292-305.

Wierzbicka, A. (1996). Semantics: Primes and universals. Oxford: Oxford University Press.

Wolff, C. E., van den Bogert, N., Jarodzka, H., \& Boshuizen, H. P. A. (2015). Keeping an eye on learning: Differences between expert and novice teachers' representations of classroom management events. Journal of Teacher Education, 66(1), 68-85. doi:10.1177/0022487114549810.

Woolfolk-Hoy, A., \& Weinstein, C. (2006). Student and teacher perspectives on classroom management. In C. Evertson \& C. Weinstein (Eds.), Handbook of Classroom Management: Research, practice and contemporary issues (pp. 181-219). Mahweh, NJ: Lawrence Erlbaum Associates.

Yamamoto, T., \& Imai-Matsumura, K. (2013). Teachers' gaze and awareness of students' behavior: Using an eyetracker. Innovative Teaching, 2(6), 1-7.

Yarbus, A. (1967). Eye movements and vision (B. Haigh \& L. A. Riggs, Trans.). New York: Plenum Press.

Zacks, J. M., Speer, N. K., Swallow, K. M., Braver, T. S., \& Reynolds, J. R. (2007). Event perception: A mind-brain perspective. Psychological Bulletin, 133(2), 273-293. doi:10.1037/0033-2909.133.2.273.

Zacks, J. M., \& Tversky, B. (2001). Event structure in perception and conception. Psychological Bulletin, 127(1), 3-21. doi:10.1037//0033-2909.127.1.3. 